\title{
DFT studies on the favored and rare tautomers of neutral and redox cytosine
}

\author{
Ewa D. Raczyńska ${ }^{1} \cdot$ Mariusz Sapuła $^{2}$ Katarzyna Zientara-Rytter ${ }^{2} \cdot$ \\ Katarzyna Kolczyńska ${ }^{2}$ Tomasz M. Stępniewski ${ }^{2} \cdot$ Małgorzata Hallmann $^{1}$
}

Received: 17 November 2015/Accepted: 19 November 2015/Published online: 10 December 2015

(C) The Author(s) 2015. This article is published with open access at Springerlink.com

\begin{abstract}
The complete tautomeric mixture consisting of nine prototropic tautomers has been studied in the gas phase at the DFT(B3LYP)/6-311+G(d,p) level for neutral, oxidized, and reduced cytosine. Rotational isomerism of the exo-OH group and geometrical isomerism of the exo $=\mathrm{NH}$ group have also been considered. Tautomeric conversions possible for cytosine have been compared with those for its structural models, 4-amino- and 2-hydroxypyrimidine. Effects of intramolecular interactions between neighboring groups for cytosine are analogous to those observed for model compounds. Although they are not very strong, they are sufficient to influence tautomeric equilibria and relative stabilities of individual tautomers. One-electron oxidation and one-electron reduction change tautomeric preferences. Tautomers that are rare forms for neutral cytosine become favored ones for oxidized and reduced cytosine. Aromaticity is not the main factor that dictates the tautomeric preferences. Stability of functional groups seems to be more important than full electron delocalization.
\end{abstract}

Keywords Cytosine - Favored and rare tautomers . Redox forms - Electron delocalization - DFT calculations

Electronic supplementary material The online version of this article (doi:10.1007/s11224-015-0710-9) contains supplementary material, which is available to authorized users.

Ewa D. Raczyńska

ewa_raczynska@sggw.pl

1 Department of Chemistry, Warsaw University of Life Sciences (SGGW), 02-776 Warsaw, Poland

2 Interdisciplinary Department of Biotechnology, SGGW, 02-776 Warsaw, Poland

\section{Introduction}

It is well recognized that prototropy in nucleobases influences the structure of nucleic acids and their replication, mutation, and degradation processes [1-13]. Labile hydrogens can move as protons between conjugated sites and change properties of nucleobases, particularly their ability to H-bonding. This phenomenon and the hypothesis of rare tautomers, suggested by Watson and Crick [2] in 1953 for DNA mutations, and later developed by Löwdin [3, 4] and advanced by Topal and Fresco [5], encouraged many chemists to theoretical and experimental studies on the structure of nucleobases in different environments. After six decades of research, although one can find in the literature hundred articles on tautomerism of nucleobases, this phenomenon attracts permanently the attention of scientists.

In normal DNA, cytosine (C) forms the H-bonded pair with guanine $(\mathrm{G})$, and adenine (A) forms the other one with thymine (T) [1]. When the tautomeric equilibrium for one base is disturbed, the pairing may be mismatched, and mutations of single nucleotide (point mutation) may appear $[2,9-13]$. When the point mutation in some genes is followed by changes in the sequence of amino acids, the changes may lead to serious diseases, e.g., cystic fibrosis, mucosal melanoma, colorectal cancer, lung cancer, and pancreatic cancer. Fortunately, the DNA mismatch repair system recognizes and repairs errors in DNA that appear during DNA replication, and only in exceptional cases this system fails to detect errors and a serious disease appears [14]. The reasons of failing are not yet well recognized, and the hypothesis of rare tautomers is continually verified by experimental and theoretical methods [9-13, 15-20].

One should mention here that experimental investigations of tautomeric conversions require exceptional efforts, 
because prototropy is a very fast and reversible process [6, $7,21]$. Prototropy is also very sensitive to experimental conditions. Individual tautomers are very difficult to separate and to study. Very frequently, experimental techniques cannot give complete information on all possible tautomeric forms and on all possible tautomeric equilibria. The principal reason is as follows. An experiment gives the possibility to identify major tautomers, signals of which have significant intensities. In some cases, minor tautomers can also be detected. Rare tautomers are usually undetectable, probably because their amounts are too small and their signals cannot be distinguished from the background. Moreover, the experimental techniques, such as ultraviolet (UV), infrared (IR), Raman, microwave (MV), nuclear magnetic resonance (NMR), and mass spectrometry (MS), have their own limits of detection, and thus, the number of detected tautomers may be different for different methods. It may also be smaller than that of possible tautomeric forms. Quantum chemical methods have this advantage that they give the possibility to study all possible individual tautomers and all intramolecular and intermolecular interactions [6, 7, 21-23]. One can also model all possible tautomeric conversions and predict all possible microscopic parameters for isolated, microsolvated and macrosolvated systems. Effects of different factors that influence stabilities of individual tautomers and their associates can also be examined. Such kind of investigations helps to understand the properties of tautomeric systems and the mechanisms of important chemical and biochemical transformations.

For our quantum chemical studies on the favored and rare tautomers of nucleic bases, we chose cytosine (Scheme 1). The reasons are as follows. Its rare tautomer may cause mutations [2]. It may form the H-bonded pair with adenine. Consequently, cytosine may be replaced by thymine during replication. The $\mathrm{GC} \rightarrow \mathrm{AT}$ transition seems to be the most frequent DNA mutations [2, 10-13, $24,25]$. Hence, it is very important to study the favored and rare tautomers of cytosine in various environments.
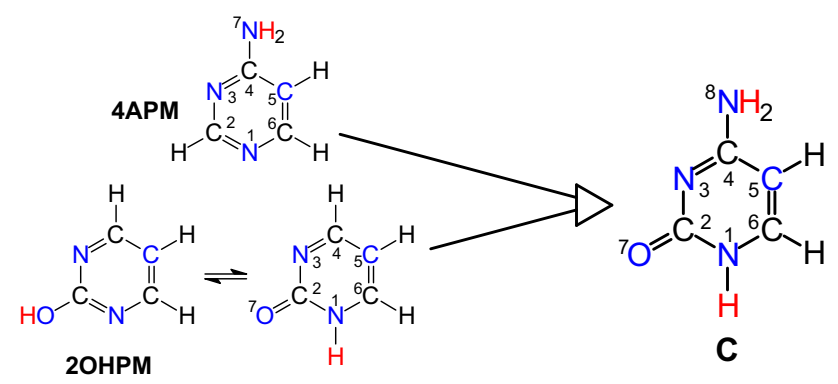

Scheme 1 Canonical form of cytosine $(\mathbf{C})$ and the structures of its convenient models, 4-amino- (4APM) and 2-hydroxypyrimidine (2OHPM). Labile protons marked in red and conjugated sites in blue (Color figure online)
Cytosine contains two labile protons and five conjugated tautomeric sites. The two protons can move according to $1,3,1,5 \mathrm{and} /$ or 1,7 proton shifts between the $\mathrm{O} 7, \mathrm{~N} 8, \mathrm{~N} 1$, $\mathrm{N} 3$, and/or C5 atoms. The proton transfers in tautomeric conversions are accompanied by migrations of one, two, and/or three double bonds, respectively, and no separation of the charge takes place $[6,21,26]$. Some proton transfers for cytosine are analogous to those for its structural models, 4-aminopyrimidine (4APM) and 2-pyrimidone-tautomeric form of 2-hydroxypyrimidine (2OHPM). Combinations of various types of tautomeric conversions, such as amide-iminol, amine-imine, and enamine-imine, lead to the complete tautomeric mixture for cytosine consisting of nine tautomers (Table 1). It should be noted here that the number of tautomers is a property of tautomeric systems. It depends on the number of labile protons and on the number of conjugated tautomeric sites [26]. However, relative stabilities of individual tautomers depend on various internal and external factors, which strongly influence tautomeric preferences [6, 7, 21]. For cytosine, the C2 (N1N8) isomer was called the 'canonical tautomer' [1]. This tautomeric form is the most frequently present in nucleic acids $[1,8,24,25]$. The C8 (N1N3) isomer, probably responsible for the point mutations of DNA, was called the rare tautomer [2].

Numerous interesting experimental and theoretical reports can be found in the literature on prototropic conversions for neutral cytosine in the gas phase. There are also some documents on microsolvated and macrosolvated cytosine. In the solid state, the canonical form $\mathbf{C 2}$ has been found for cytosine [27]. In the gas phase, depending on the experimental method applied (matrix isolation IR, MW, REMPI, IR laser in helium nanodroplets, MS, core-level $\mathrm{X}$-ray photoemission, and near-edge X-ray absorption), two $(\mathbf{C 1}$ and $\mathbf{C 2})$ or three $(\mathbf{C 1}, \mathbf{C 2}$, and C8) tautomers have been detected for cytosine [28-35]. Recently, five isomers of gaseous cytosine (two rotational isomers $\mathbf{a}$ and $\mathbf{b}$ of $\mathbf{C 1}$, one isomer of $\mathbf{C 2}$, and two geometrical isomers $\mathbf{a}$ and $\mathbf{b}$ of

Table 1 Positions of labile protons for tautomers of cytosine $(\mathbf{C})$, 4-amino- (4APM), and 2-hydroxypyrimidine (2OHPM)

\begin{tabular}{llll}
\hline Tautomer & Position of $\mathrm{H}$ & Tautomer & Position of $\mathrm{H}$ \\
\hline C1 & O7N8 & 4APM1 & N7 \\
C2 & N1N8 & 4APM2 & N1 \\
C3 & N3N8 & 4APM3 & N3 \\
C4 & C5N8 & 4APM4 & C5 \\
C5 & O7N1 & 2OHPM1 & O7 \\
C6 & O7N3 & 2OHPM2 & N1 \\
C7 & O7C5 & 2OHPM3 & N3 \\
C8 & N1N3 & 2OHPM4 & C5 \\
C9 & N3C5 & & \\
\hline
\end{tabular}


C8) have been characterized by Alonso et al. [36], who applied a laser-ablation molecular-beam Fourier-transform microwave (LA-MB-FT-MW) spectroscopy. In aqueous solution, two tautomeric forms of cytosine (C2 and $\mathbf{C 3})$ seem to dominate [37].

Unfortunately, the complete tautomeric mixture of cytosine has not been investigated by quantum chemical methods [38-50]. Maximum six tautomers have been studied for neutral cytosine (C1-C3, C5, C6, and C8), and the amide-iminol and amine-imine conversions analyzed [40-42]. In some papers, even rotational isomerism of the exo $-\mathrm{OH}$ group and geometrical isomerism of the exo $=\mathrm{NH}$ group have not been considered. The enamine-imine conversions and the $\mathrm{CH}$ tautomers $(\mathbf{C 4}, \mathbf{C 7}$, and $\mathbf{C 9})$ have usually been neglected. Favored and rare tautomers have solely been studied for adiabatically bound valence anions of cytosine, and the importance of the $\mathbf{C 9}$ tautomer discussed [51]. The $\mathrm{CH}$ tautomer has also been found to be favored for negatively ionized 4APM [52, 53].

The hypothesis of rare tautomers and also the variability of tautomeric preferences for the adiabatically bound valence anions of cytosine and for the ionized forms of 4APM encouraged us to undertake the studies for the complete tautomeric mixture of cytosine at various oxidation states, the neutral $(\mathbf{C})$, oxidized $\left(\mathbf{C}-\mathrm{e} \rightarrow \mathbf{C}^{+}\right)$, and reduced $\left(\mathbf{C}+\mathrm{e} \rightarrow \mathbf{C}^{--}\right)$states in the gas phase. In the literature, one-electron oxidation and one-electron reduction are also called positive and negative ionization in mass spectrometry, or electron detachment and electron attachment in photoelectron spectroscopy. In this work, tautomeric conversions and various internal effects such as substituent effects and intramolecular interactions between neighboring groups have been discussed for the neutral and redox forms of cytosine. Geometric and energetic consequences of prototropy have also been examined and compared to those observed earlier for 4APM and 2OHPM. For investigations, the DFT method [54] has been employed with the hybrid functional of Becke [55] and gradient correction of Lee et al. (B3LYP) [56] and the 6-311+G(d,p) basis set [57] as previously described for adenine and its models [52, 53, 58, 59]. The B3LYP functional has been recommended for charged radicals [60] and applied for the anionic states of nucleic bases [51]. It has also been used for geometry optimalization in the G3B3 theory [61].

\section{Methods}

Geometries of the neutral and charged forms of all possible cytosine isomers in their ground states (Fig. 1) were fully optimized in the gas phase without symmetry constraints

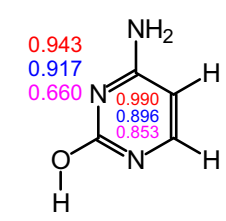

C1a $(1.4,0.4,11.9)$

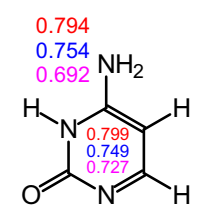

C3 $(7.0,0.0,4.6)$

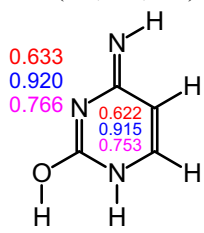

C5ab $(32.4,18.5,32.0)$

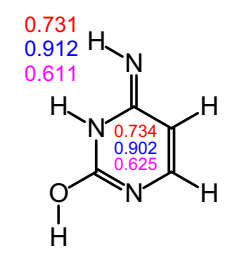

C6aa $(17.3,6.3,21.9)$

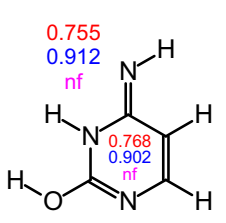

C6bb $(21.9,11.2, \mathrm{nf})$

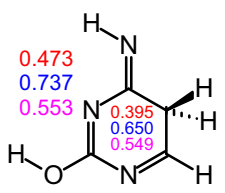

C7ba $(31.3,39.6,8.3)$

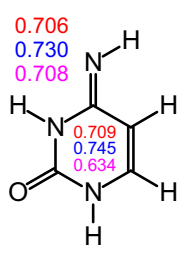

C8b $(2.2,1.7,4.0)$

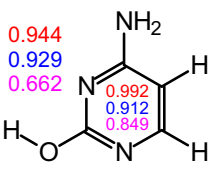

C1b $(2.1,0.8,12.8)$

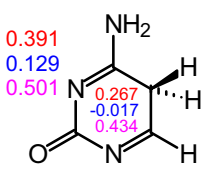

C4 $(21.4,25.6,10.6)$

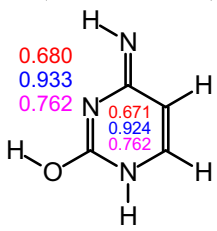

C5ba $(19.0,6.2,29.9)$

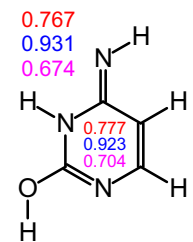

C6ab (14.5, 3.5, 19.7)

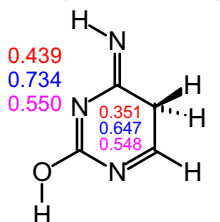

C7aa $(32.2,39.0,9.0)$

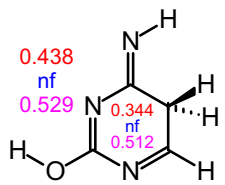

C7bb (35.6, nf, 12.3)

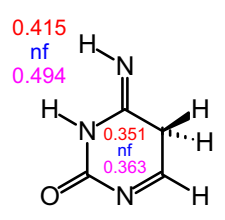

C9a (19.1, nf, 0.6)

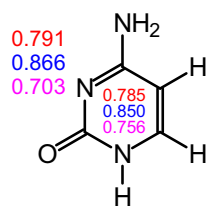

C2 $(0.0,0.6,1.5)$

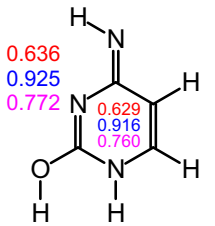

C5aa $(28.1,14.9,27.7)$

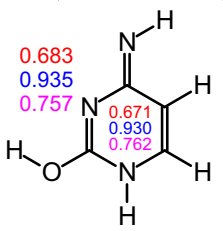

C5bb (22.4, 9.6, 32.6)

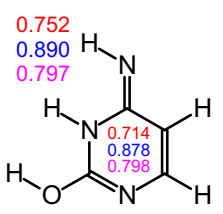

C6ba $(24.7,15.0,25.4)$

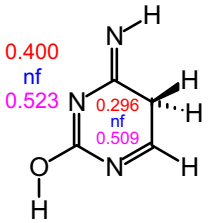

C7ab (37.3, nf, 13.7)

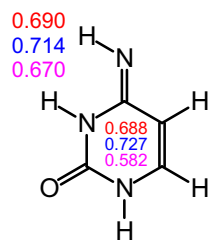

C8a (3.9, 2.8, 7.0)

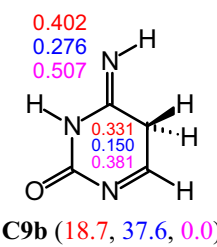

Fig. 1 All possible isomers of cytosine. The relative Gibbs energies (in kcal mol ${ }^{-1}$ at $298.15 \mathrm{~K}$ ) and the HOMED indices estimated for neutral (red), oxidized (blue), and reduced (rose) cytosine (nfstructure not found at the DFT level). $\Delta G$ given in parentheses. HOMED6 and HOMED8 placed inside and outside of the ring, respectively (Color figure online) 
employing the DFT(B3LYP) method [54-56] and the 6-311+G(d,p) basis set [57]. The restricted B3LYP functional was used for neutral isomers, and the unrestricted B3LYP functional was applied for charged radicals. For all structures, frequencies were calculated, first to prove that the structures are minima and next to estimate the corresponding zero-point energies. Thermodynamic parameters such as the energy $(E)$, enthalpy $(H=E+\mathrm{p} V)$, entropy $(S)$, and Gibbs energy $(G=H-T S$ for $T=298.15 \mathrm{~K})$ were calculated using the same level of theory. For tautomeric conversions, the relative thermodynamic parameters $(\Delta E, \Delta H, T \Delta S$, and $\Delta G)$, the tautomeric equilibrium constants (as $\mathrm{p} K=\Delta G / 2.303 \mathrm{R} T$ ), and the percentage contents of individual forms $\{x=K /(1+K)\}$ were estimated. The $\Delta G$ values include changes in the electronic energy, zero-point energy (ZPE), and thermal corrections to the energy and entropy (vibrational, rotational, and translational). The theoretical adiabatic ionization potential $\{\mathrm{IP}=E($ optimized radical cation $)-E($ optimized neutral) $\}$ and the theoretical adiabatic electron affinity $\{\mathrm{EA}=E$ (optimized neutral) $-E$ (optimized radical anion) $\}$ were calculated for the tautomeric mixture, taking the total energies of the neutral and charged forms at their respective equilibrium nuclear configurations, and their percentage contents in the tautomeric mixture were also considered. All calculations were performed according to the procedures included in the Gaussian- 03 series of programs [62].

To properly determine the distribution of $\pi$ - and $n$ electrons for all tautomers/rotamers of cytosine and to well describe the variations of electron delocalization, the geometry-based HOMED (harmonic oscillator model of electron delocalization) procedure $[63,64]$ was applied to the geometries optimized at the DFT(B3LYP)/6$311+\mathrm{G}(\mathrm{d}, \mathrm{p})$ level. The abbreviation HOMED was proposed in 2006 for the modified index [63], but it may also be abbreviated as moHOMA (modified original HOMA) or simply HOMA. The HOMA (harmonic oscillator model of aromaticity) index [65, 66], reformulated by Krygowski [67], and the HOMHED (harmonic oscillator model of heterocyclic electron delocalization) index, proposed by Frizzo and Martins in 2012 [68] and based on hypotheses of the HOMED index [64], were not applied here for cytosine. The reasons were discussed previously [53, 69]. Since the same resonance phenomenon takes place for neutral molecules, ions, and radicals [26], the HOMED indices were estimated for neutral and redox forms of cytosine using the following equation: $\mathrm{HOMED}=1-\left\{\alpha(\mathrm{CC}) \times \Sigma\left[R_{\mathrm{O}}(-\right.\right.$ $\left.\left.\mathrm{CC})-R_{i}(\mathrm{CC})\right]^{2}+\alpha(\mathrm{CX}) \times \Sigma\left[R_{\mathrm{o}}(\mathrm{CX})-R_{i}(\mathrm{CX})\right]^{2}\right\} / n$. In this equation, $\alpha$ are the normalization constants, $R_{\mathrm{o}}$ are the optimum bond lengths (assumed to be realized for fully delocalized systems), $R_{i}$ are the running bond lengths in the tautomeric system, and $n$ is the number of bonds taken into account. In the case of cytosine isomers, six bonds for the pyrimidine ring and eight bonds for the whole molecule, including the exo $-\mathrm{OH} /=\mathrm{O}$ and $-\mathrm{NH}_{2} /=\mathrm{NH}$ groups, were taken into account. The normalization $\alpha$ constants for the even number of bonds were calculated from the following equation: $\alpha=2 \times\left[\left(R_{\mathrm{o}}-R_{\mathrm{S}}\right)^{2}+\left(R_{\mathrm{o}}-R_{\mathrm{d}}\right)^{2}\right]^{-1}$, where $R_{\mathrm{s}}$ and $R_{\mathrm{d}}$ are the reference single and double bonds, respectively. The following $R_{\mathrm{s}}, R_{\mathrm{d}}$, and $R_{\mathrm{o}}$ values (in $\AA$ ), calculated at the B3LYP/6-311+G(d,p) level for the reference molecules, were taken here [64]: 1.530 (ethane), 1.329 (ethene), and 1.394 (benzene) for the CC bonds; 1.466 (methylamine), 1.267 (methylimine), and 1.334 (1,3,5-triazine) for $\mathrm{CN}$ bonds; and 1.424 (methanol), 1.202 (formaldehyde), and 1.281 (protonated carbonic acid) for the CO bonds. On the basis of these $R$ values, the normalization $\alpha$ constants equal to $88.09,91.60$, and 75.0 were used for the $\mathrm{CC}, \mathrm{CN}$, and $\mathrm{CO}$ bonds, respectively [64].

\section{Results and discussion}

For the hydroxy forms of cytosine (C1 and C5-C7), two rotational isomers can be considered, one with the hydroxy $\mathrm{H}$ atom synperiplanar to the endo $\mathrm{N} 1$ atom (a) and the other one with this atom synperiplanar to the endo N3 atom (b). Due to geometrical isomerism of the exo $=\mathrm{NH}$ group, two isomers are also possible for the imino forms of cytosine (C5-C9), one with the imino $\mathrm{H}$ atom synperiplanar to the endo N3 atom (a) and the other one with this atom synperiplanar to the endo $\mathrm{C} 5$ atom (b). Taking into account all type of isomerism possible for cytosine (tautomerism, rotational, and geometrical isomerism), the structures of twenty-one neutral isomers were optimized at the DFT(B3LYP)/6-311+G** level (Fig. 1). The same number of isomers was considered for the charged radicals, and their structures optimized at the DFT level. For the thermodynamically stable structures, the relative Gibbs energies $(\Delta G)$ were calculated, and the HOMED indices estimated for the ring (six bonds-HOMED6) and for the whole tautomeric system, including the exo $-\mathrm{NH}_{2} /=\mathrm{NH}$ and $-\mathrm{OH} /=\mathrm{O}$ groups (eight bonds-HOMED8). All calculated $\Delta G$ and HOMED values are given in Fig. 1.

The minima with real frequencies were found for all possible twenty-one isomers of neutral cytosine. For the amino tautomers, the exo $\mathrm{NH}_{2}$ group is not in the ring plane [43]. It has a pyramidal conformation. For the imino tautomers, transfer of labile proton(s) to the endo $\mathrm{N}$ atom(s) in C2, C3, C5, C6, and $\mathbf{C 8}$ does not destroy the planarity of the ring. Solely the $\mathrm{CH}$ amino $(\mathbf{C 4})$ and imino tautomers (C7 and C9) lose the planarity of the ring due to the presence of the $\mathrm{C} 5-\mathrm{sp}^{3}$ atom. For positively charged forms (radical cations), three isomers $\mathbf{C 7} \mathbf{a b}^{+\cdot}, \mathbf{C} 7 \mathbf{b b}^{+}$, and $\mathbf{C 9}^{+\cdot}$ were not found. The exo $=\mathrm{NH}$ group in the 
thermodynamically stable $\mathbf{C 7} \mathbf{a a}^{+\cdot}, \mathbf{C 7 b a}^{+\cdot}$, and $\mathbf{C} \mathbf{9 b} \mathbf{b}^{+}$ isomers is out of the ring plane by the dihedral angle equal to 34,37 , and $62^{\circ}$, respectively. The exo $=\mathrm{NH}$ group is also twisted for $\mathbf{C 5} \mathbf{a b}^{+\cdot}$ and $\mathbf{C 5} \mathbf{b b}^{+\cdot}$ by 51 and $24^{\circ}$, respectively. The exo $\mathrm{NH}_{2}$ group is planar for all positively charged amino forms. For radical anions, this group takes the pyramidal conformation. Solely one isomer $\mathbf{C} 6 \mathbf{b b}^{-}$ was not found for negatively charged cytosine. The exo $=\mathrm{NH}$ group in all stable negatively charged isomers is almost in the ring plane. The dihedral angle is not larger than $5^{\circ}$

Positions of labile protons and oxidation states strongly influence the $\mathrm{CC}, \mathrm{CN}$, and $\mathrm{CO}$ bond lengths for the cytosine isomers. The effects are not parallel for neutral and redox forms. This suggests that there is no common mechanism for one-electron oxidation and separately for one-electron reduction for all cytosine isomers. An analysis of the total atomic spin densities confirms the differences. Various exo and endo heteroatoms and/or $\pi$ bonds lose one electron in cytosine tautomers. One electron is also gained by different sites. The differences have already been observed for the hydroxy and amino derivatives of azines [53]. Consequently, the HOMED indices estimated for the six-membered ring (HOMED6) as well as for the whole molecule including the exo groups (HOMED8) vary in a different way for the neutral and ionized amino-hydroxy, amino-oxo, imino-hydroxy, and imino-oxo isomers, and there is no linear relation between the HOMED indices of the neutral and ionized forms (Fig. 2).

The HOMED8 values for neutral isomers of cytosine vary from 0.39 to 0.94 . The $\mathbf{C 1 a}$ and $\mathbf{C 1 b}$ isomers have the largest HOMED values (close to unity), and they are aromatic. The $\mathbf{C 4}$ isomer has the lowest HOMED value, and it is non-aromatic due to the presence of the $\mathrm{C} 5-\mathrm{sp}^{3}$ atom in the ring. The HOMED indices of the other $\mathrm{CH}$ isomers with the $\mathrm{C}^{-}$-sp ${ }^{3}$ atom $(\mathbf{C 7 a a}, \mathbf{C 7} \mathbf{a b}, \mathbf{C 7 b a}, \mathbf{C 7 b b}, \mathbf{C 9 a}$, and C9b) are only slightly larger (HOMED8 0.40-0.47) than

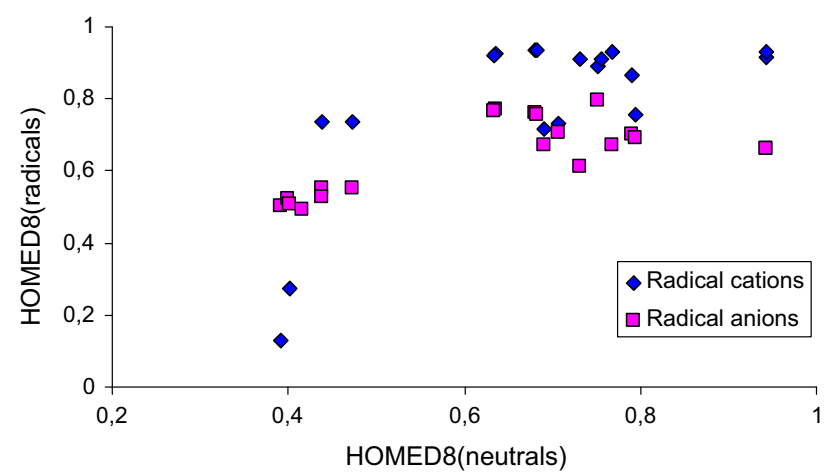

Fig. 2 Plots between the HOMED8 indices of neutral and ionized forms of cytosine that of $\mathbf{C 4}$. The canonical tautomer $\mathbf{C 2}$ is less delocalized (HOMED8 0.79) than the C1a and C1b isomers, but it is still aromatic. Similar $\pi$-electron delocalization has been previously reported for the canonical tautomer using various measures of aromaticity [70-73]. The N1 atom in C2 taking the labile proton retains its planarity. The $n-\pi$ conjugation in the six-membered ring of $\mathbf{C 2}$ is similar to that for the five-membered ring in pyrrole, imidazole, etc. [64].

One-electron oxidation dramatically changes bond lengths and electron delocalization for all cytosine isomers. Consequently, the geometry-based indices (HOMED6 and HOMED8) also change. They decrease for the $\mathrm{CH}-\mathrm{NH}$ isomers $\left(\mathbf{C 4}^{+\cdot}\right.$ and $\left.\mathbf{C 9} \mathbf{b}^{+\cdot}\right)$ even to zero, while they increase for the $\mathrm{CH}-\mathrm{OH}$ ones $\left(\mathbf{C 7}^{\mathbf{a a}^{+\cdot}}\right.$ and $\left.\mathbf{C} 7 \mathbf{b a}^{+}\right)$to $0.73-0.74$. They also increase for the imine $\mathrm{NH}-\mathrm{OH}$ isomers $\left(\mathbf{C 5}^{+} \mathbf{a a}^{+*}\right.$,

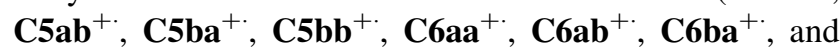
$\mathbf{C} \mathbf{6} \mathbf{b b}^{+}$, HOMED8 $\geq 0.89$ ) and for the canonical NH-NH form $\mathbf{C 2}^{+\cdot}$ (HOMED8 0.87). However, they slightly decrease for the $\mathrm{NH}-\mathrm{OH}$ isomers $\mathbf{C 1 a}^{+\cdot}$ and $\mathbf{C 1 b}^{+}$. (HOMED8 0.92 and 0.93, respectively). One-electron reduction causes also different effects. For negatively ionized cytosine isomers, the HOMED8 values vary solely from 0.49 to 0.80 . For the canonical form $\mathbf{C 2}^{-*}$, the HOMED8 value slightly decreases (to 0.70 ) when compared to the neutral form. In higher degree, the HOMED8 values decrease for the $\mathrm{NH}-\mathrm{OH}$ isomers $\mathbf{C 1 a}^{-\cdot}$ and $\mathbf{C 1 b}^{-}$. (0.66). Interestingly, the HOMED8 values increase for the CH tautomers (0.49-0.55). Similar tendencies for the HOMED indices have been observed for model compounds $[52,53]$.

The relative entropy term $(T \Delta S)$ values are not very large $\left( \pm 1 \mathrm{kcal} \mathrm{mol}^{-1}\right)$ for neutral and charged isomers of cytosine, similar to other tautomeric systems $[21,52,53$, $58,59]$. This indicates that all tautomeric conversions for cytosine (Scheme S1, Supplementary Material) are isoentropic processes in the gas phase. There are no large structural changes during tautomerization. Some exceptions are those for the amine and imine $\mathrm{CH}$ tautomers. They are a consequence of the ring planarity loss. The relative thermal corrections for all tautomeric conversions are also close to zero, and $\Delta E \cong \Delta H \cong \Delta G$. These observations suggest that the relative thermodynamic parameters depend very little on temperature. When proceeding from 0 to $298.15 \mathrm{~K}$, orders of the relative energies for major isomers do not change for neutral and charged cytosine. Generally, proton transfer reactions are isoentropic for almost all organic acids and bases [74, 75]. The relative entropies and the relative thermal corrections are close to zero.

First, perusal of the relative Gibbs energies calculated for neutral isomers of cytosine gives the possibility to distinguish the following characteristic properties for 
major, minor, and rare tautomers. All $\mathrm{CH}$ isomers $(\mathbf{C 4}, \mathbf{C 7}$, and C9) can be considered as very rare forms for neutral cytosine $\left(\Delta G \gg 10 \mathrm{kcal} \mathrm{mol}^{-1}\right)$. Indeed, the proton transfers from the $\mathrm{N} 1, \mathrm{~N} 3, \mathrm{O} 7$, or $\mathrm{N} 8$ atom to the $\mathrm{C} 5$ atom are very unfavorable processes, and all $\mathrm{CH}$ isomers can be neglected for neutral cytosine. Analogous conclusions have been derived for model compounds, 4APM [52] and 2OHPM [53], using the same level of theory. The $\mathrm{CH}$ tautomers (4APM4 and 2OHPM4) can be neglected for neutral 4APM and 2OHPM $\left(\Delta G \gg 10 \mathrm{kcal} \mathrm{mol}^{-1}\right)$. The imino $\mathrm{OH}-\mathrm{NH}$ forms $\left(\Delta G \gg 10 \mathrm{kcal} \mathrm{mol}^{-1}\right)$ containing one labile proton at the $\mathrm{O} 7$ and the other one at the N1 (C5) or N3 atom (C6) can also be considered as very rare forms, and thus, they can also be neglected for neutral cytosine. They are analogous to the imino $\mathrm{NH}$ forms of $\mathbf{4 A P M}$ (4APM2 and 4APM3) [52]. One exception is the imino $\mathrm{NH}-\mathrm{NH}$ form with labile protons at the $\mathrm{N} 1$ and $\mathrm{N} 3$ atoms (C8), typical for the pyrimidine bases (uracil, thymine, and cytosine). Its two rotamers $\mathbf{a}$ and $\mathbf{b}\left(\Delta G 2-4 \mathrm{kcal} \mathrm{mol}^{-1}\right)$ can be considered as minor forms rather than rare isomers for neutral cytosine (Scheme 2). The amino C2 and C3 $(\mathrm{NH}-\mathrm{NH})$ tautomers with one labile proton at the N1 and $\mathrm{N} 3$ atoms, respectively, are analogous to 2OHPM2 and 2OHPM3. For model compound, 2OHPM2 and 2OHPM3 are identical. They have identical thermodynamic stabilities and the same energies [53]. However, the presence of the exo $\mathrm{NH}_{2}$ group at the 4-position in cytosine strongly differentiates relative stabilities of $\mathbf{C 2}$ and $\mathbf{C 3}$. The $\mathbf{C 3}$ tautomer can be considered as rare amino form $\left(\Delta G 7 \mathrm{kcal} \mathrm{mol}^{-1}\right.$ ), whereas the $\mathbf{C} \mathbf{2}$ tautomer is the favored 'canonical' form for neutral cytosine at the B3LYP level $\left(\Delta G 0 \mathrm{kcal} \mathrm{mol}^{-1}\right)$. The two rotamers $\mathbf{a}$ and $\mathbf{b}$ of the amino C1 $(\mathrm{NH}-\mathrm{OH})$ tautomer with labile proton at the $\mathrm{O} 7$ atom are major amino forms $\left(\Delta G \leq 2 \mathrm{kcal} \mathrm{mol}^{-1}\right)$.

The presence of all five major and minor isomers (C1a, C1b, C2, C8a, and C8b) in the tautomeric mixture of

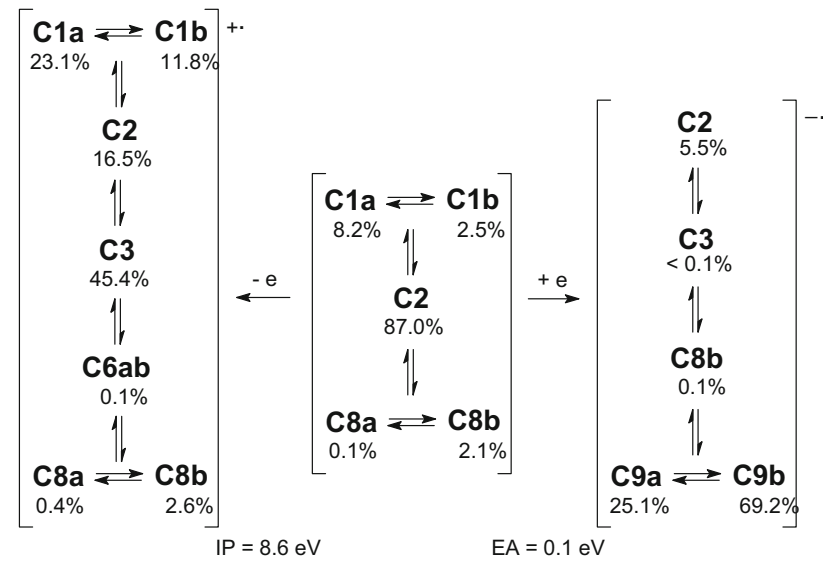

Scheme 2 Favored redox processes for cytosine estimated at the DFT level neutral cytosine has been experimentally proven [36]. Our DFT calculations are in good agreement with those reported in the literature [39-42, 47, 49]. However, it should be mentioned here that the percentage contents of major and minor forms depend on the level of calculations [38-50] as well as on the experimental method applied [30-36]. For example, the DFT methods predict the canonical tautomer $\mathbf{C 2}$ as the favored form for neutral cytosine, whereas the HF, MPn and CC methods indicate the C1a isomer. Table S1 (Supplementary Material) lists some selected DFT, HF, MPn, and CC data for the five major and minor tautomers of cytosine. Differences in the predicted $\Delta E$ values are not larger than $2 \mathrm{kcal} \mathrm{mol}^{-1}$. On the other hand, Brown et al. [31], using the MW spectroscopy to jet-cooled cytosine with a nozzle temperature of $568 \mathrm{~K}$, estimated the populations of $\mathbf{C} 2$ and C1a to be in the approximate ratio 1:1 in the gas phase. Alonso et al. [36], who applied the LA-MB-FT-MW spectroscopy, found recently a slight predominance of C1a and concluded that ab initio calculations did not reproduce well the experimental observations. When compared to thymine and uracil, cytosine is a very complex molecular system. The common conclusion on its major tautomers (C2 and C1a) in the gas phase has not yet been formulated. The microhydration by one, two, or three water molecules $[42,45,46]$ and the macrohydration by using the continuum models [40, 41, 45, 48, 49] favor the 'canonical' tautomer $\mathbf{C 2}$.

One-electron oxidation changes the relative energies of all individual isomers (Fig. 1), and consequently, it changes the composition of the tautomeric mixture (Scheme 2). The tautomeric mixture of oxidized cytosine consists of four major forms $\left(\mathbf{C 1 a}^{+\cdot}, \mathbf{C 1 b}^{+}, \mathbf{C} 2^{+\cdot}\right.$, and $\mathbf{C 3}^{+\cdot}$, $\Delta G<1 \mathrm{kcal} \mathrm{mol}^{-1}$ ), three minor forms $\left(\mathbf{C 6} \mathbf{a b}^{++}, \mathbf{C 8 a}^{+}\right.$, and $\mathbf{C 8 b ^ { + }}, \Delta G$ 2-4 $\mathrm{kcal} \mathrm{mol}^{-1}$ ), and three rare forms $\left(\mathbf{C 5 b a}^{+}, \mathbf{C 5 b b}^{+\cdot}\right.$, and $\mathbf{C 6 a a}^{+}, \Delta G$ 6-10 $\left.\mathrm{kcal} \mathrm{mol}^{-1}\right)$. The other isomers have $\Delta G$ larger than $10 \mathrm{kcal} \mathrm{mol}^{-1}$. They may be neglected in the tautomeric mixture of positively ionized cytosine. Most dramatical changes in the tautomeric mixture of cytosine are caused by one-electron reduction. The $\mathrm{CH}$ isomers $\mathbf{C 9}^{-\cdot}$ and $\mathbf{C 9} \mathbf{b}^{-*}$, very rare forms for neutral and oxidized cytosine, become the favored structures for reduced cytosine. The Gibbs energy of the reduced canonical form $\mathbf{C 2}^{-}$is larger by ca. $1 \mathrm{kcal} \mathrm{mol}^{-1}$ than that of $\mathbf{C 9}^{-}$, and those of $\mathbf{C 1 a}^{--}$and $\mathbf{C 1 b}^{-\cdot}$ are larger by more than $10 \mathrm{kcal} \mathrm{mol}^{-1}$ than that of $\mathbf{C 9 b}^{--}$. The tautomeric mixture of reduced cytosine consists of three major forms $\left(\mathbf{C} 2^{--}, \mathbf{C 9} \mathbf{a}^{-}\right.$, and $\mathbf{C 9}^{-}$, $\left.\Delta G<2 \mathrm{kcal} \mathrm{mol}^{-1}\right)$, two minor forms $\left(\mathbf{C 3}^{-\cdot}\right.$ and $\mathbf{C 8 b}^{-}$, $\Delta G 4-5 \mathrm{kcal} \mathrm{mol}^{-1}$ ), and three rare forms $\left(\mathbf{C 7 a a}^{-}\right.$, $\mathbf{C 7 b a}^{-}$, and $\mathbf{C 8 a}^{-\cdot}, \Delta G 7-9 \mathrm{kcal} \mathrm{mol}^{-1}$ ). The other isomers have $\Delta G$ values larger than $10 \mathrm{kcal} \mathrm{mol}^{-1}$. They may be neglected for negatively ionized cytosine. 
The variations of the composition of the tautomeric mixture when proceeding from neutral to redox cytosine (Scheme 2) seem to originate from a combination of the analogous variations observed for model compounds, 4APM (Scheme S2) and 2OHPM (Scheme S3) estimated at the same level of theory. The aromatic amine tautomer predominates in the gas phase for neutral and oxidized 4APM, whereas the non-aromatic $\mathrm{CH}$ imino isomer is favored for reduced 4APM [52]. For 2-hydroxypyrimidine, the oxo tautomers dominate in the tautomeric mixture for neutral, oxidized, and reduced forms [53]. Moreover, direct comparison of the DFT calculated thermodynamic parameters for the oxidized and neutral isomers of 4-aminopyrimidine, 2-hydroxypyrimidine, and cytosine indicates that one-electron oxidation is very endothermic process and requires ca. $200 \mathrm{kcal} \mathrm{mol}^{-1}$. One-electron reduction is more profitable process than one-electron oxidation and requires considerably lower energy. Both model compounds and cytosine may take spontaneously one electron from a reducing agent.

There are no experimental data in the literature for the ionization potential (IP) and for the electron affinity (EA) of model compounds for comparison [74, 75]. However, it should be mentioned here that the literature IPs for 4-aminopyridine (8.8 eV [76]), 2-aminopyridine $(8.5 \mathrm{eV}$ [76]), and unsubstituted pyrimidine (9.3 eV [75]) are of the same order of magnitude as the DFT estimated adiabatic IPs for 4-aminopyrimidine $(8.8 \mathrm{eV})$ and 2-hydroxypyrimidine $(9.1 \mathrm{eV})$. On the other hand, the literature EA for unsubstituted pyrimidine is not very large: EA (electron transmission spectroscopy) $-0.25 \mathrm{eV}$ [77] and EA (G2MP2B3) -0.17 eV [74]. Taking the composition of the tautomeric mixture for neutral and ionized cytosine into account, one can estimate the IP $(8.6 \mathrm{eV})$ and EA $(0.1 \mathrm{eV})$ values in the gas phase for the favored ionization processes at the DFT level (Scheme 2). They are close to those for model compounds (Schemes S2 and S3). The experimental IP value for cytosine (8.45 eV [78]) is not very different from the DFT one. Schiedt et al. [79] found two EA values for the cytosine dipole bound state, one for the amino-oxo tautomer $(0.23 \mathrm{eV})$ and the other one for the amino-hydroxy tautomer $(0.08 \mathrm{eV})$. For the valence state of the rare $\mathrm{CH}$ tautomer, $\mathrm{Li}$ et al. [51] estimated larger EA value (2.34 eV).

Comparison of the relative Gibbs energies estimated at the DFT level for cytosine isomers with those estimated at the same level of theory for analogous isomers of 2OHPM and 4APM gives the possibility to estimate the total energetic effects $(\delta G)$ of the exo $\mathrm{NH}_{2}$ and $\mathrm{OH}$ groups. These effects, $\delta G\left(\mathrm{NH}_{2}\right)$ and $\delta G(\mathrm{OH})$, include the classical inductive and resonance electronic substituent effects of the exo $\mathrm{NH}_{2}$ and $\mathrm{OH}$ groups and also the additional internal effects being a consequence of specific favorable and unfavorable interactions of the exo with endo neighboring groups. The $\delta G\left(\mathrm{NH}_{2}\right)$ and $\delta G(\mathrm{OH})$ values can be estimated for neutral and redox forms of cytosine for selected tautomeric conversions, which are analogous to those for model compounds.

The $\delta G$ values of the exo $\mathrm{NH}_{2}$ group were found (Table 2), when cytosine was considered as the amino derivative of 2OHPM. Proceeding from 2OHPM to cytosine, the total energetic effects of the exo $\mathrm{NH}_{2}$ group $(\delta G)$ on the iminol-amide and iminol-iminon conversions were estimated as differences between the relative Gibbs energies of analogous tautomeric conversions for cytosine and 2OHPM $\left\{\delta G\left(\mathrm{NH}_{2}\right)=\Delta G(\right.$ cytosine $\left.)-\Delta G(\mathbf{2 O H P M})\right\}$. For neutral forms, larger effects (4-5 kcal mol${ }^{-1}$ ) occur for the $\mathrm{C1} \rightarrow \mathrm{C} 3$ and $\mathrm{C1} \rightarrow \mathrm{C4}$ conversions than for the $\mathrm{C1} \rightarrow \mathrm{C2}$ one $\left(\delta G \leq 3 \mathrm{kcal} \mathrm{mol}^{-1}\right)$. The reasons are as follows. For $\mathbf{C 4}$, the $\mathrm{NH}_{2}$ group can interact unfavorably with the $\mathrm{C}_{5} \mathrm{H}_{2}$ group. For $\mathbf{C 3}$, the $\mathrm{NH}_{2}$ group can interact unfavorably with the $\mathrm{N} 3 \mathrm{H}$ and $\mathrm{C} 5 \mathrm{H}$ groups, whereas for $\mathbf{C 2}$ an interaction between the $\mathrm{NH}_{2}$ group and the $\mathrm{N} 3$ atom can be favorable. For C1a and C1b, interactions between the $\mathrm{OH}$ group and the $\mathrm{N} 1$ or N3 atom are favorable. A similar tendency occurs for the reduced forms, for which one excess electron is taken by the ring for 2OHPM and cytosine. The $\delta G\left(\mathrm{NH}_{2}\right)$ values are larger for the $\mathbf{C 1} \rightarrow \mathbf{C 3}$ and $\mathbf{C 1} \rightarrow \mathbf{C 4}$ conversions $\left(\delta G>2 \mathrm{kcal} \mathrm{mol}^{-1}\right)$ than for the $\mathbf{C 1} \rightarrow \mathbf{C 2}$ one ( $\delta G 0.1 \mathrm{kcal} \mathrm{mol}^{-1}$ ). However, one-electron oxidation strongly increases the total effects of the exo $\mathrm{NH}_{2}$ group $\left(\delta G \geq 7 \mathrm{kcal} \mathrm{mol}^{-1}\right)$. This group is favored for one electron loss in cytosine.

When cytosine was considered as the hydroxy derivative of 4 APM, the total energetic effects of the exo $\mathrm{OH}$ group $(\delta G)$ were calculated for the amine-imine and enamineimine conversions. Table 3 summarizes the $\delta G(\mathrm{OH})$ values for the conformations $\mathbf{a}$ and $\mathbf{b}$ of the $\mathrm{OH}$ group. They were estimated as differences between the relative Gibbs energies of analogous tautomeric conversions for cytosine and 4APM $\{\delta G(\mathrm{OH})=\Delta G($ cytosine $)-\Delta G(\mathbf{4 A P M})\}$. The largest effects $\left(\delta G>5 \mathrm{kcal} \mathrm{mol}^{-1}\right)$ occur for tautomeric

Table 2 Total energetic effects of the exo $\mathrm{NH}_{2}$ group $(\delta G$ in $\mathrm{kcal} \mathrm{mol}^{-1}$ ) on selected tautomeric conversions for cytosine analogous to those for 2OHPM

\begin{tabular}{lcll}
\hline Conversion & $\delta G\left(\mathrm{NH}_{2}\right)$ & & \\
\cline { 2 - 4 } & Neutral & Radical cation & Radical anion \\
\hline $\mathbf{C 1 a} \rightarrow \mathbf{C 2}$ & -2.2 & 8.1 & -0.1 \\
$\mathbf{C 1 b} \rightarrow \mathbf{C 2}$ & -3.0 & 7.7 & -0.1 \\
$\mathbf{C 1 a} \rightarrow \mathbf{C 3}$ & 4.7 & 7.5 & 3.0 \\
$\mathbf{C 1 b} \rightarrow \mathbf{C 3}$ & 4.0 & 7.1 & 2.1 \\
$\mathbf{C 1 a} \rightarrow \mathbf{C 4}$ & -4.7 & 7.3 & -4.3 \\
$\mathbf{C 1 b} \rightarrow \mathbf{C 4}$ & -5.4 & 6.9 & -5.2 \\
\hline
\end{tabular}


conversions of neutral isomers, for which the $\mathrm{OH}$ group interacts unfavorably with the N1H (C5aa and C5ab) or $\mathrm{N} 3 \mathrm{H}$ group (C6ba and C6bb). When intramolecular interactions between neighboring groups are favorable, the total effects of the exo $\mathrm{OH}$ group are considerably lower, and the $\delta G$ values do not exceed $4 \mathrm{kcal} \mathrm{mol}^{-1}$. A similar tendency and slightly larger $\delta G$ values are found for oxidized cytosine. For reduced cytosine, variations of the $\delta G$ values are not parallel to those for neutral and oxidized cytosine. However, the $\delta G$ values are not larger than $8 \mathrm{kcal} \mathrm{mol}^{-1}$.

A relation between prototropy and electron delocalization has been signaled more than 50 years ago by Pauling [26]. This relation has been recently discussed for some simple tautomeric systems [21]. Good linear relationships have been found for the neutral aromatic NH and nonaromatic $\mathrm{CH}$ tautomers of imidazole and purine, which have no substituent, and which possess solely the endo functional groups [52, 53, 80-83]. Prototropy is also well related to electron delocalization for the neutral $\mathrm{NH}$ and $\mathrm{CH}$ tautomers of aminoazines and for the $\mathrm{NH}-\mathrm{NH}$ and $\mathrm{NH}-\mathrm{CH}$ tautomers of adenine [52, 53, 81]. Aminoazines and adenine contain not only the endo aza group(s) but also the exo $-\mathrm{NH}_{2} /=\mathrm{NH}$ group. For particular isomers, the exo group can interact intramolecularly with the endo functional groups. Since these internal effects are less important factors than aromaticity, they only slightly perturb the relation between prototropy and electron delocalization for neutral aminoazines and adenine.

Quite a different situation takes place for hydroxyazines and uracyl, which contain the exo $-\mathrm{OH} /=\mathrm{O}$ functional group(s) [53]. The relation between prototropy and electron delocalization seems to be more complex. The energetic

Table 3 Total energetic effects of the exo $\mathrm{OH}$ group ( $\delta G$ in $\mathrm{kcal} \mathrm{mol}^{-1}$ ) on selected tautomeric conversions for cytosine analogous to those for 4APM

\begin{tabular}{lccc}
\hline Conversion & $\delta G(\mathrm{OH})$ & & \\
\cline { 2 - 4 } & Neutral & Radical cation & Radical anion \\
\hline C1a $\rightarrow$ C5aa & 8.5 & 12.7 & 1.5 \\
C1a $\rightarrow$ C5ab & 8.8 & 11.9 & 2.1 \\
$\mathbf{C 1 b} \rightarrow$ C5ba & -1.3 & 3.6 & 2.8 \\
C1b $\rightarrow$ C5bb & -1.9 & 2.6 & 1.8 \\
C1a $\rightarrow$ C6aa & -0.3 & 1.1 & 5.4 \\
C1a $\rightarrow$ C6ab & -0.2 & 1.2 & 5.4 \\
C1b $\rightarrow$ C6ba & 6.4 & 9.4 & 8.0 \\
C1b $\rightarrow$ C6bb & 5.9 & 8.9 & - \\
C1a $\rightarrow$ C7aa & -1.4 & -3.8 & 2.0 \\
C1a $\rightarrow$ C7ab & -0.9 & - & 2.1 \\
C1b $\rightarrow$ C7ba & -3.0 & -3.6 & 0.4 \\
C1b $\rightarrow$ C7bb & -3.3 & - & -0.2 \\
\hline
\end{tabular}

parameters $(\Delta G)$, which measure prototropy, are not parallel to the geometric ones (HOMED), which measure electron delocalization. We observe similar tendency for cytosine, which possesses one exo-OH/=O group (Fig. 3). Stability of functionalities seems to be more important factor than aromaticity and seems to dictate the tautomeric preferences for neutral cytosine. Intramolecular interactions between the exo and endo groups influence also the conformational and configurational preferences for the hydroxy and imino tautomers. For ionized cytosine, the HOMED $8 / \Delta G$ plots are more complex. There is no common HOMED8/ $\Delta G$ relationship for radical cations nor for radical anions.

However, when cytosine is considered as the 4-amino derivative of 2-hydroxypyrimidine (2OHPM), variations of the HOMED indices estimated for the whole tautomeric system of neutral cytosine isomers and those of their relative Gibbs energies $(\Delta G)$ are almost analogous to those for neutral 2OHPM (Fig. 4). The iminol-amide and iminol-iminon conversions for cytosine cause geometric changes similar to those for 2OHPM [53]. Some differences take place for energetic parameters, particularly for the iminol-amide conversions, i.e., between the $\mathbf{C 2}$ and $\mathbf{C 3}$ isomers of cytosine and 2OHPM2/2OHPM3.

Interestingly, when cytosine is considered as the 2-hydroxy derivative of 4-aminopyrimidine, a plot between the HOMED indices estimated for the whole tautomeric system (eight bonds) and the relative Gibbs energies calculated for the neutral C1a, C1b, C5aa, C5ab, C5ba, C5bb, C6aa, C6ab, C6ba, C6bb, C7aa, C7ab, C7ba, and C7bb isomers is similar to that found previously [52] for the corresponding neutral 4AMP isomers (Fig. 5). The amine-imine and enamine-imine conversions for neutral cytosine cause almost parallel changes of the geometric (HOMED) and energetic $(\Delta G)$ parameters. Some stronger deviations of points for cytosine than those for 4APM may result from intramolecular interactions (favorable or unfavorable) between the exo $\mathrm{OH}$ and endo $\mathrm{N} 1 / \mathrm{N} 1 \mathrm{H}$ or $\mathrm{N} 3 / \mathrm{N} 3 \mathrm{H}$ group in two different conformations (a and $\mathbf{b}$ ) of the $\mathrm{OH}$ group. These interactions influence stronger the relative Gibbs

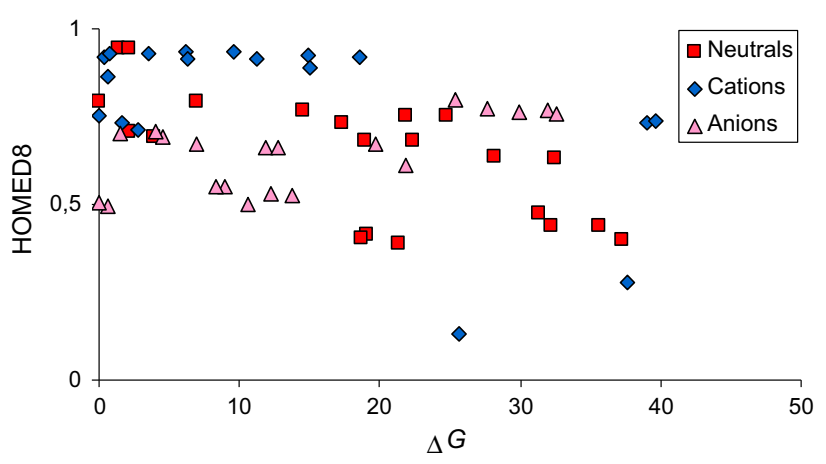

Fig. 3 HOMED8/ $\Delta G$ plots for neutral (red points), oxidized (blue points), and reduced (rose points) cytosine (Color figure online) 


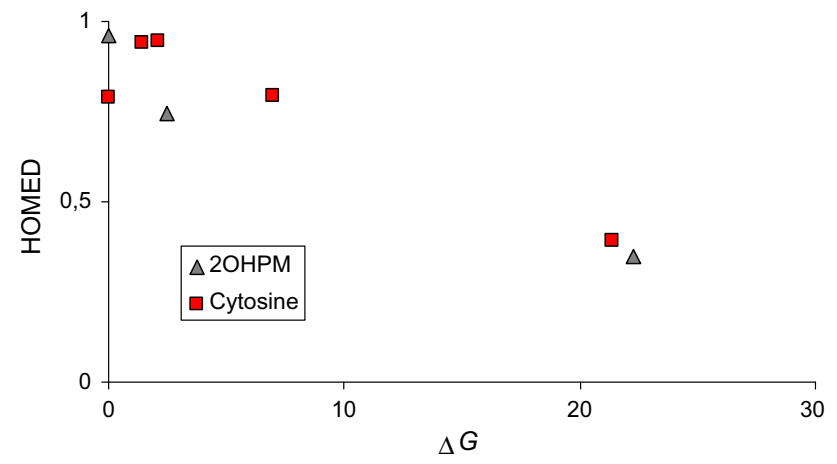

Fig. 4 Plots between the HOMED indices and the $\Delta G$ values (in $\mathrm{kcal} \mathrm{mol}^{-1}$ ) estimated for neutral 2-hydroxypyrimidine (2OHPM) isomers (gray points) and for analogous neutral isomers in cytosine (red points) considered as the 4-amino derivative of 2OHPM (Color figure online)

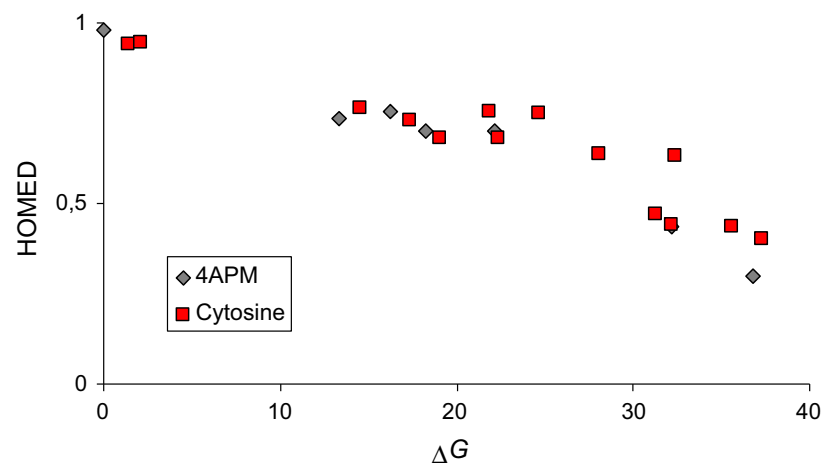

Fig. 5 Plots between the HOMED indices and the $\Delta G$ values (in $\mathrm{kcal} \mathrm{mol}^{-1}$ ) estimated for neutral 4-aminopyrimidine (4APM) isomers (gray points) and for analogous neutral cytosine isomers (red points), considered as the 2-hydroxy derivative of 4APM (Color figure online)

energies than the HOMED indices. For example, differences between the $\Delta G$ values for the rotational isomers C5aa and C5ba, C5ab and C5bb, C6aa and C6ba, and C6ab and C6bb are close to 7-10 $\mathrm{kcal} \mathrm{mol}^{-1}$, whereas those between the HOMED8 values are considerably lower and close to $0.01-0.05$. Rotation of the exo $=\mathrm{NH}$ group and consequently intramolecular interactions (favorable or unfavorable) between this group and the endo $\mathrm{N} 3 / \mathrm{N} 3 \mathrm{H}$ or $\mathrm{C}_{5} \mathrm{H}_{i}(i=1$ or 2) group cause lower energetic effects $\left(\leq 5 \mathrm{kcal} \mathrm{mol}^{-1}\right)$ than rotation of the $\mathrm{OH}$ group. Geometric effects $(0.00-0.04$ HOMED units) are not very large for the exo $=\mathrm{NH}$ group. They are similar to those for the exo $\mathrm{OH}$ group.

\section{Conclusions}

The DFT calculations performed for the complete tautomeric mixture of neutral and redox cytosine consisting of all possible twenty-one isomers show clearly that prototropy affects weaker the geometric parameters than the energetic ones. When proceeding from the neutral to oxidized (positively ionized) or reduced (negatively ionized) form of cytosine, the composition of the tautomeric mixture changes significantly (Scheme 2). The rare tautomers for neutral cytosine become the favored ones for oxidized and reduced cytosine. These variations seem to originate from those observed earlier for models, 4-aminoand 2-hydroxypyrimidine [52, 53].

There is no good relation between the geometric (HOMED) and energetic $(\Delta G)$ parameters estimated for individual isomers of cytosine (Fig. 3). This indicates that aromaticity is not the main factor that influences the tautomeric preferences. High stability of the amide form for cytosine is similar to that for 2-pyrimidone [53]. It destroys the relation between the geometric and energetic parameters for the amide-iminol conversions (Fig. 4). A good relation exists solely for the amine-imine and enamineimine conversions (Fig. 5). It is similar to that found previously for 4-aminopyrimidine [52]. Deviations of some points result from intramolecular interactions between neighboring groups.

For cytosine included in the DNA acid, solely seven isomers may be considered (C2, C5aa, C5ab, C5ba, $\mathbf{C 5 b b}, \mathbf{C 8 a}$, and $\mathbf{C 8 b}$ ). The DFT calculations clearly show that the $\mathbf{C 8}$ tautomer, proposed by Watson and Crick as the rare form [2], is present in the tautomeric mixture of cytosine at each oxidation state. The $\mathbf{C 8}$ tautomer may be responsible for the point mutation of DNA. Four isomers of C5 may be neglected in the tautomeric mixture. Further studies for the 1-alkyl derivative of cytosine may give some quantitative estimation of the contribution of $\mathbf{C 2}$ and C8 in the DNA nucleotide when oxidizing or reducing agents appear in living organisms.

Open Access This article is distributed under the terms of the Creative Commons Attribution 4.0 International License (http://crea tivecommons.org/licenses/by/4.0/), which permits unrestricted use, distribution, and reproduction in any medium, provided you give appropriate credit to the original author(s) and the source, provide a link to the Creative Commons license, and indicate if changes were made.

\section{References}

1. Watson JD, Crick FHC (1953) Nature 171:737-738

2. Watson JD, Crick FHC (1953) Nature 171:964-967

3. Löwdin P-O (1963) Rev Mod Phys 35:724-732

4. Löwdin P-O (1965) Adv Quantum Chem 2:213-360

5. Topal MD, Fresco JR (1976) Nature 263:285-289

6. Elguero J, Marzin C, Katritzky AR, Linda P (1976) The tautomerism of heterocycles. Academic Press, New York

7. Pozharskii AF, Soldatenkov AT, Katritzky AR (1997) Heterocycles in life and society. Wiley, New York 
8. Saenger W (1994) Principles of nucleic acids structure. Springer, New York

9. Florián J, Goodman M, Warshel A (2002) J Phys Chem B 106:5739-5753

10. Grebneva HA (2003) J Mol Struct 645:133-143

11. Grebneva HA (2006) Environ Mol Mutagen 47:733-745

12. Danilov VI, Stewart JJP, Leś A, Alderfer JL (2000) Chem Phys Lett 328:75-82

13. Danilov VI, Anisimov VM, Kurita N, Hovorun D (2005) Chem Phys Lett 412:285-293

14. Peña-Diaz J, Jiricny J (2012) Trends Biochem Sci 37:206-214

15. Leszczynski J (ed) (1999) Computational molecular biology: theoretical and computational chemistry, vol 8. Elsevier, New York

16. Hobza P, Šponer J (1999) Chem Rev 99:3247-3276

17. Lippert B, Gupta D (2009) Dalton Trans 4619-4634

18. Serrano-Andrés L, Merchán M (2009) J Photochem Photobiol C Photochem Rev 10:21-32

19. Brovarets' OO, Kolomiets IM, Hovorun DM (2012) Quantumchemistry models for innovations. In: Toda $\mathrm{T}$ (ed) Tech. http:// cdn.intechopen.com/pdfs-wm/33305.pdf

20. Singh V, Fedeles BI, Essigmann JM (2015) RNA 21:1-13

21. Raczyńska ED, Kosińska W, Ośmiałowski B, Gawinecki R (2005) Chem Rev 105:3561-3612

22. Kwiatkowski JS, Pullman B (1975) Adv Heterocycl Chem 18:199-335

23. Kwiatkowski JS, Person WB (1990) In: Beveridge DL, Lavery R (eds) Theoretical biochemistry and molecular biology. Academic Press, New York, pp 153-171

24. Griffits AJF, Gelbart WM, Miller JH, Lewontin RC (1999) Modern genetic analysis. Freeman WH, New York

25. Berg JM, Tymoczko JL, Stryer L (2002) Biochemistry, 5th edn. New York, Freeman WH

26. Pauling L (1960) The nature of chemical bond, 3rd edn. Cornell University Press, New York

27. McClure RJ, Craven BM (1973) Acta Crystallogr Sect B 29:1234-1238

28. Radchenko ED, Sheina GG, Smorygo NA, Blagoi YP (1984) J Mol Struct 116:387-396

29. Kuczera K, Szczesniak M, Szczepaniak K (1988) J Mol Struct 172:101-112

30. Szczesniak M, Szczepaniak K, Kwiatkowski JS, Kubulat K, Person WB (1988) J Am Chem Soc 110:8319-8330

31. Brown RD, Godfrey PD, Mc Naughton D, Pierlot AP (1989) J Am Chem Soc 111:2308-2310

32. Nir E, Müller M, Grace LI, de Vries MS (2002) Chem Phys Lett 355:59-64

33. Choi MY, Dong F, Miller RE (2005) Phil Trans R Soc A 363:393-413

34. Wolken JK, Chunxiang Y, Tureček F, Polce MJ, Wesdemiotis C (2007) Int J Mass Spectrom 267:30-42

35. Feyer V, Plekan O, Richter R, Coreno M, Vall-llosera G, Prince KC, Trofimov AB, Zaytseva IL, Moskovskaya TE, Gromov EV, Schirmer J (2009) J Phys Chem A 113:5736-5742

36. Alonso JL, Vaquero V, Peña I, López JC, Mata S, Caminati W (2013) Ang Chem Int Ed 52:2331-2334

37. Dreyfus M, Bensaude O, Dodin G, Dubois JE (1976) J Am Chem Soc 98:6338-6349

38. Kwiatkowski JS, Bartlett RJ, Person WB (1988) J Am Chem Soc 110:2353-2358

39. Kobayashi R (1998) J Phys Chem A 102:10813-10817

40. Sambrano JR, de Souza AR, Queralt JJ, Andrés J (2000) Chem Phys Lett 317:437-443

41. Fazaeli R, Monajjemi M, Ataherian F, Zare K (2002) J Mol Struct (Theochem) 581:51-58
42. Mazzuca D, Marino T, Russo N, Toscano M (2007) J Mol Struct (Theochem) 811:161-167

43. Fogarasi G (2002) J Phys Chem A 106:1381-1390

44. Fogarasi G (2008) Chem Phys 349:204-209

45. Trygubenko SA, Bogdan TV, Rueda M, Orozco M, Luque FJ, Šponer J, Slavíček P, Hobza P (2002) Phys Chem Chem Phys 4:4192-4203

46. Shukla MK, Leszczyński J (2002) J Phys Chem A 106:11338-11346

47. Chandra AK, Michalska D, Wysokinsky R, Zeegers-Huyskens T (2004) J Phys Chem A 108:9593-9600

48. Friedman H, Nguyen HN, Truong TN (2004) J Phys Chem B 108:19043-19048

49. Sathyabama V, Anandan K, Kanagaraju R (2009) J Mol Struct (Theochem) 897:106-110

50. Zheng HT, Zhao DX, Yang ZZ (2011) Chin J Chem 29:2243-2248

51. Li X, Bowen KH, Haranczyk M, Bachorz RA, Mazurkiewicz K, Rak J, Gutowski M (2007) J Chem Phys 127:174309

52. Raczyńska ED, Kolczyńska K, Stępniewski TM (2012) J Mol Model 18:3523-3533

53. Raczyńska ED (2014) Comput Theor Chem 1042:8-15

54. Parr RG, Yang W (1998) Density functional theory of atoms and molecular orbital theory. Oxford University Press, New York

55. Becke AD (1993) J Chem Phys 98:5648-5652

56. Lee C, Yang W, Parr RG (1988) Phys Rev B 37:785-789

57. Hehre WJ, Radom L, PvR Schleyer, Pople JA (1986) Ab initio molecular theory. Wiley, New York

58. Raczyńska ED, Makowski M, Zientara-Rytter K, Kolczyńska K, Stępniewski TM, Hallmann M (2013) J Phys Chem A 117:1548-1559

59. Raczyńska ED, Stępniewski TM, Kolczyńska K (2011) J Mol Model 17:3229-3239

60. Riestra-Kiracofe JC, Tschumper GS, Schaefer HF III, Nandi S, Ellison GB (2002) Chem Rev 102:231-282

61. Baboul AG, Curtiss LA, Redfem PC, Raghavachari K (1999) J Chem Phys 110:7650-7657

62. Frisch MJ, Trucks GW, Schlegel HB, Scuseria GE, Robb MA, Cheeseman JR, Montgomery JA Jr, Vreven T, Kudin KN, Burant JC, Millam JM, Iyengar SS, Tomasi J, Barone V, Mennucci B, Cossi M, Scalmani G, Rega N, Petersson R, Nakatsuji H, Hada M, Ehara M, Toyota K, Fukuda R, Hasegawa J, Ishida M, Nakajima T, Honda Y, Kitao O, Nakai H, Klene M, Li X, Knox JE, Hratchian HP, Cross JB, Bakken V, Adamo C, Jaramillo R, Gomperts R, Stratmann RE, Yazyev O, Austin AJ, Cammi R, Pomelli C, Ochterski JW., Ayala PY, Morokuma K, Voth GA, Salvador P, Dannenberg JJ, Zakrzewski VG, Dapprich S, Daniels $\mathrm{AD}$, Strain MC, Farkas O, Malick DK, Rabuck AD, Raghavachari K, Foresman JB, Oritz JV, Cui Q, Baboul AG, Clifford S, Cioslowski J, Stefanov BB, Liu G, Liashenko A, Piskorz P, Komaromi I, Martin RL, Fox DJ, Keith T, Al-Laham MA, Peng CY, Nanayakkara A, Challacombe M, Gill PMW, Johnson B, Cheng, Wong MW, Gonzalez C, Pople JA (2004) Gaussian-03, Revision E.01, Gaussian, Inc., Wallingford

63. Raczyńska ED, Krygowski TM, Duczmal K, Hallmann M (2006) XVIII International Conference on Physical Organic Chemistry, Warsaw (Book of abstracts, p. 31)

64. Raczyńska ED, Hallmann M, Kolczyńska K, Stępniewski TM (2010) Symmetry 2:1485-1509

65. Kruszewski J, Krygowski TM (1972) Tetrahedron Lett 13:3839-3842

66. Krygowski TM, Kruszewski J (1974) Bull Acad Pol Sci. Sér Sci Chim 22:871-876

67. Krygowski TM (1993) J Chem Inf Comput Sci 33:70-78

68. Frizzo CP, Martin MP (2012) Struct Chem 23:375-380 
69. Raczyńska ED, Kolczyńska K, Stępniewski TM, Kamińska B (2013) Comput Theor Chem 1022:35-44

70. Cyrański MK, Gilski M, Jaskólski M, Krygowski TM (2003) J Org Chem 68:8607-8613

71. Cysewski P (2005) J Mol Struct (Theochem) 714:29-34

72. Huertas O, Poater J, Fuentes-Cabrera M, Orozco M, Sola M, Luque FJ (2006) J Phys Chem A 110:12249-12258

73. Sun GY, Nicklaus MC (2007) Theoret Chem Acc 117:323-332

74. Bartmess JE NIST Chemistry WebBook, NIST Standard Reference Database Number 69. Linstrom PJ, Mallard WG (Eds), National Institute of Standards and Technology, Gaithersburg MD, 20899. htpp://webbook.nist.gov

75. Lias SG in NIST Chemistry WebBook, NIST Standard Reference Database Number 69. Linstrom PJ, Mallard WG (Eds), National Institute of Standards and Technology, Gaithersburg MD, 20899. htpp://webbook.nist.gov
76. Stefanovic D, Grützmacher HF (1974) Org Mass Spectrom 9:1052-1054

77. Nenner I, Schultz GJ (1975) J Chem Phys 62:1747-1758

78. Dougherty D, Younathan ES, Voll R, Abdulnur S, McGlynn SP (1978) J Electron Spectrosc Relat Phenom 13:379-393

79. Schiedt J, Weinkauf R, Neumark DM, Schlag EW (1998) Chem Phys 239:511-524

80. Raczyńska ED, Kamińska B (2013) J Mol Model 19:3947-3960

81. Raczyńska ED, Kolczyńska K, Stępniewski TM, Kamińska B (2013) Comput Theor Chem 1022:35-44

82. Raczyńska ED, Makowski M (2014) J Mol Model 20:2234

83. Raczyńska ED, Makowski M, Hallmann M, Kamińska B (2015) RSC Adv 5:36587-36604 